\title{
O arquivamento e a disponibilização dos produtos audiovisuais universitários do Curso de Jornalismo da Universidade Federal do Cariri
}

\section{Paulo Eduardo Silva Lins Cajazeira}

Doutor em Comunicação e Semiótica Pontifícia Universidade Católica de São Paulo. Professor Associado I da Universidade Federal do Cariri.

paulo.cajazeira@ufca.edu.br

José Jullian Gomes de Souza

Mestre em Biblioteconomia pela Universidade Federal do Cariri.

jullianjose64@gmail.com

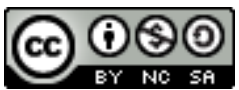

Este trabalho está licenciado com uma Licença Creative Commons - AtribuiçãoNãoComercial-Compartilhalgual 3.0 Brasil.

\section{Resumo}

Este estudo busca analisar como os processos de aprendizado estão para além das etapas de produção e pós-produção do produto audiovisual universitário, partindo da seguinte problemática: como as práticas de arquivamento e disponibilização online do produto audiovisual jornalístico desenvolvem novas formas de consumo e aprendizado no ambiente universitário? Enquanto objetivo geral buscamos compreender como ocorrem as práticas de arquivamento e disponibilização dos produtos audiovisuais nas plataformas online. E, os objetivos específicos: a) mapear as plataformas online de disponibilização, utilizadas pelo Curso de Jornalismo da UFCA e; b) refletir sobre as novas formas de consumo audiovisual a partir dos avanços tecnológicos no ambiente digital. A metodologia é caracterizada por uma abordagem quanti-qualitativa, levantamento bibliográfico e coleta dos produtos audiovisuais com recorte entre os anos de 2013 a 2019. Dessa forma, identifica-se como o arquivamento, disponibilização e consumo estão presentes no diálogo com os ambientes digitais de informação. Uma vez que esses lugares funcionam enquanto ambientes memorialísticos e de consumo audiovisual.

Palavras-chave: Produto audiovisual jornalístico. Práticas de arquivamento. Ambientes digitais de informação.

\section{Archiving and making available university audiovisual products from the Journalism Course at the Federal University of Cariri}

\section{Abstract}

This study seeks to analyze how the learning processes are beyond the production and post-production stages of the university audiovisual product, starting from the following problem: how the archival practices and online availability of the journalistic audiovisual product develop new forms of consumption and learning in the university environment? As a general objective, we seek to understand how archival practices and the availability of audiovisual product on online platforms occur. And, the specific objectives: a) map the online platforms of availability, used by the UFCA Journalism Course and; b) reflect on the new forms of audiovisual consumption based on technological advances in the digital environment. The methodology is characterized by a quanti-qualitative approach, bibliographic survey and collection of audiovisual products with clipping between the years 2013 to 2019. In this way, it is identified how the archiving, availability and consumption are present in the dialogue with the digital environments of information. Since these places function as memorial and audiovisual consumption environments.

Keywords: Journalistic audiovisual product. Archiving practices. Digital information environments. 


\section{Reflexões introdutórias}

Os processos de produção e disponibilização dos produtos audiovisuais jornalísticos perpassam por diversos contextos, quando se reflete desde a sua inicialização até o seu acesso. Esses processos são vastos, múltiplos e repletos de aprendizados indo desde a escolha da temática abordada, as etapas de pré-produção, as entrevistas, captação das imagens e a pós-produção, com o objetivo de finalizar a edição para a sua exibição como produto informacional de um registro documental. Essas etapas e procedimentos podem ser vislumbrados no contexto das universidades, a partir dos cursos de Jornalismo no Brasil, a exemplo do Curso de Jornalismo da Universidade Federal do Cariri (UFCA), um dos 39 cursos de jornalismo em universidades federais brasileiras. Uma vez que se tem nas disciplinas vinculadas ao telejornalismo, o contato com a linguagem e formato audiovisual.

Além do processo de produção é pertinente e necessário a discussão sobre o arquivamento e a disponibilização desses produtos audiovisuais jornalísticos. Visto que, são esses estágios que impulsionam a circulação dos produtos, a troca e apropriação de informação e a geração de conhecimento através do acesso, uso e recuperação da informação audiovisual sobretudo em ambientes digitais situados com as novas Tecnologias da Informação e Comunicação (TICs). Assim,

São as novas tecnologias de informação e sua disseminação, que modificaram aspectos fundamentais, tanto da condição da informação quanto, da condição da sua distribuição. Estas tecnologias intensas modificaram radicalmente a qualificação de tempo e espaço entre as relações do emissor, com os estoques e os receptores da informação (BARRETO, 2007, p. 28).

Dessa forma, é possível o vislumbramento das transmutações do desenvolvimento com esses produtos audiovisuais no ambiente universitário, partindo das experiências laboratoriais do Curso de Jornalismo da UFCA que está situada na região sul do Estado do Ceará, Nordeste do Brasil. Na qual a problemática acerca do tema de pesquisa proposto, proporciona uma reflexão a ser discutida a nível teórico-pragmático, gerando resultados para serem aplicados no cotidiano desses ambientes informacionais audiovisuais na contemporaneidade.

Assim, tem-se a seguinte problemática: como as práticas de arquivamento e disponibilização online do produto audiovisual jornalístico desenvolvem novas formas de consumo e aprendizado no ambiente universitário? Aponta-se como objetivo geral do estudo compreender como ocorrem as práticas de arquivamento e disponibilização dos produtos audiovisuais nas plataformas online. E, como objetivos específicos: a) mapear as plataformas online de disponibilização, utilizadas pelo Curso de Jornalismo da UFCA e; b) refletir sobre as novas formas de consumo audiovisual a partir dos avanços tecnológicos no ambiente digital.

A pesquisa sobre os produtos audiovisuais jornalísticos no âmbito universitário, perpassa a esfera dos estudos sobre os arquivos e documentos audiovisuais jornalísticos direcionando a pesquisa para a interdisciplinaridade de três campos do conhecimento: Biblioteconomia, Ciência da Informação (BCl) e a Comunicação, com ênfase no Jornalismo. Essas três áreas lidam de formas diferentes com o objeto de estudo. Enquanto as duas primeiras se situam no processo de organização e representação da informação; a terceira é responsável pela produção audiovisual.

Além disso, destaca-se a relevância em discorrer sobre os resgistros audiovisuais, visto que "[...] só ultimamente passaram a ser compreendidos como documentos e reconhecidos como patrimônio a ser preservado e divulgado" (TÁRTAGLIA; BRUTUCE, 2015, p. 331). Dessa forma, compreende-se a significação da realização do estudo e do apronfundamento da pesquisas decorrentes da interdisciplinaridade entre e $\mathrm{BCl}$ e o Jornalismo.

\section{Trabalho de Conclusão de Curso: o produto audiovisual jornalístico}

O Trabalho de Conclusão de Curso (TCC) é uma disciplina obrigatória na matriz curricular na maioria dos cursos de graduação no Brasil. No TCC o estudante desenvolve uma reflexão teórica ou teórico-prática - dependendo do curso e instituição - que dialoga com o seu conhecimento adquirido ao longo dos semestres de disciplinas teóricas e práticas, discussões e aprendizados em sala de aula na vivência com os professores e colegas de turma. No Projeto Pedagógico do Curso (PPC) de Jornalismo (UNIVERSIDADE FEDERAL DO CARIRI, 2016), a disciplina de TCC ocorre no oitavo semestre, com carga 
horário de 320 horas. Tal disciplina é precedida por outra, Pesquisa em Comunicação no sétimo semestre, em que o estudante direciona a sua pesquisa e o seu modelo de TCC com o apoio do professor que ministra a disciplina.

As modalidades do TCC podem variar de instituição para instituição e de curso para curso. Especificamente no Curso de Jornalismo da UFCA, o estudante encontra duas opções: a monografia e o produto jornalístico. A escolha por uma dessas duas possibilidades deve ocorrer no semestre anterior. Assim, o estudante tem cerca de um ano para o início do desenvolvimento da pesquisa até a conclusão para em seguida realizar a defesa do seu TCC, como um dos componentes obrigatórios para o término da graduação em Jornalismo.

Ao discorrer sobre o produto jornalístico, o PPC do Curso de Jornalismo explica que o

[...] Produto Jornalístico permite que o (a) aluno (a) desenvolva, de forma experimental, a criação de um produto jornalístico que possa contribuir para o amadurecimento profissional. A disciplina está relacionada ao campo da experimentação, mas exige rigor necessário à realização dos trabalhos, partindo do pressuposto de que o (a) aluno (a) esteja apto (a) a ingressar formalmente no mercado de trabalho. É premissa fundamental para o desenvolvimento do projeto, que o trabalho a ser desenvolvido tenha ou viabilidade comercial (mercadológica) ou relevância cultural (UNIVERSIDADE FEDERAL DO CARIRI, 2016 p. 129).

É interessante observar com a possibilidade advinda com o desenvolvimento de um produto jornalístico, que o foco se volta para a questão prática e experimental cujo objetivo é proporcionar ao estudante um contato ainda mais próximo com o cotidiano da profissão. Assim, o Curso de Jornalismo oferta as seguintes modalidades de produtos jornalísticos categorizadas em nove modalidades como observadas a seguir:

Quadro 1 - Modalidades de produtos jornalísticos para o trabalho de conclusão de curso PRODUTO JORNALISTICO DESCRIÇÃO

Livro-reportagem

Revista

Jornal

Plano de comunicação de uma assessoria de comunicação

Fotografia (fotojornalismo)

Documentário televisivo
Com o objetivo de realizar um livro-reportagem, o (a) aluno (a) deverá desenvolver um projeto em que deverá constar a redação final e edição do material no suporte livro.

Com o objetivo de produzir uma revista, o (a) aluno (a) deverá desenvolver um projeto (com escolha definida entre o projeto redacional e o projeto gráfico) em que deverá constar a captação das informações a partir das premissas estabelecidas no item anterior, sem permissão de inserção de publicidade.

Com o objetivo de produzir um jornal, o (a) aluno (a) deverá desenvolver um projeto (com escolha definida entre o projeto redacional e o projeto gráfico) em que deverá constar a redação final e edição do material no suporte jornal.

Com o objetivo de realizar um Plano de Comunicação, o (a) aluno (a) deverá desenvolver um projeto em que deverá constar a execução de um Plano capaz de contemplar os diferentes públicos a serem atingidos (interno, externo e imprensa), com estratégias específicas para cada um deles.

Com o objetivo de apresentar um projeto fotográfico, o (a) aluno (a) deverá desenvolver uma série que contemple tema de relevância jornalística e (ou) documental. O produto poderá ser um ensaio ou fotorreportagem, com proposta apontando para a relevância do tema escolhido, detendo aprofundamento no assunto e perspectivas plurais de investigação. Este trabalho deverá ser acompanhado de uma apresentação do assunto a ser abordado. A apresentação final poderá ser uma reportagem fotográfica ou uma fotodocumentação.

Com o objetivo de desenvolver um documentário televisivo, o (a)aluno (a) deverá desenvolver um projeto em que conste a captação e edição final do 


\begin{tabular}{|c|c|}
\hline & $\begin{array}{l}\text { documentário. O documentário deverá ter um mínimo de } \\
\text { quinze minutos. Pode ser feito por até três pessoas, } \\
\text { sendo a avaliacão individual. }\end{array}$ \\
\hline Grande reportagem televisiva & $\begin{array}{l}\text { Consiste numa série de cinco videorreportagens } \\
\text { temáticas, que abordem o mesmo assunto. Ou seja, o } \\
\text { aluno, até o número de quatro, realizará cinco } \\
\text { videorreportagens que constituirão uma série jornalística } \\
\text { televisiva com tempo total de } 15 \text { minutos. Não há } \\
\text { regulação individual de tempo das videorreportagens. }\end{array}$ \\
\hline Documentário radiofônico & $\begin{array}{l}\text { Com o objetivo de desenvolver um documentário } \\
\text { radiofônico, o (a)aluno (a) deverá desenvolver um } \\
\text { projeto em que conste a captação e edição final do } \\
\text { documentário. O documentário deverá ter um mínimo de } \\
\text { trinta minutos. }\end{array}$ \\
\hline $\begin{array}{l}\text { Produção de um programa em formato } \\
\text { radiorevista ou produto multimídia } \\
\text { (webdocumentário) }\end{array}$ & $\begin{array}{l}\text { O aluno (a) deverá desenvolver um projeto que } \\
\text { contemple uma narrativa jornalística numa perspectiva } \\
\text { multimidiática, sendo esta compreendida como um } \\
\text { conjunto convergente dos modos enunciativos vídeo, } \\
\text { áudio, texto, imagem estática e interatividade, de } \\
\text { maneira que a combinação destas diversas modalidades } \\
\text { enunciativas crie uma narrativa jornalística em suporte } \\
\text { hipertextual digital. Dessa maneira, o (a) aluno (a) } \\
\text { poderá desenvolver um documentário para a web. }\end{array}$ \\
\hline
\end{tabular}

Fonte: Elaborado pelos autores a partir do PPC de Jornalismo (UNIVERSIDADE FEDERAL DO CARIRI, 2016).

Dentre tais modalidades, três podem ser destacadas em relação ao produto audiovisual: o documentário de TV, a grande reportagem de TV e o webdocumentário. São as três experiências nas quais os estudantes podem experimentar a produção audiovisual universitária para a elaboração dos seus TCCs. Os fundamentos basilares para tal feito ocorrem partir da vivência nas disciplinas de telejornalismo durante a graduação, que estão subdivididas em três semestre durante 0 curso:

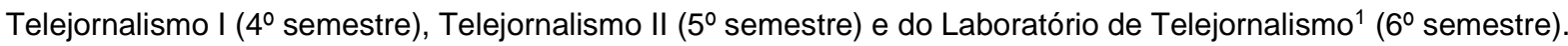

\subsection{Arquivamento, disponibilização e formas de consumo}

Nesta subseção atenta-se para as questões acerca do arquivamento, disponibilização e formas de consumo identificando a relação com o objeto de estudo do artigo: o produto audiovisual jornalístico universitário. Dessa forma, compreende-se que a necessidade do arquivamento vai além das fronteiras de registro dessas memórias audiovisuais, seja para a disponibilização interna, na qual os próprios estudantes, técnicos e professores podem ter acesso dentro do centro de arquivo do curso de Jornalismo podendo consumir ou consultar; ou externa, em que os demais sujeitos tanto do curso como da universidade ou sociedade possam acessar e visualizar esses produtos audiovisuais.

Ou seja, a ideia de arquivamento tem como objetivo propiciar a preservação, mas também a disponibilização visando o acesso, uso, consumo e a recuperação da informação audiovisual, que pode ocorrer tanto em sua forma física quanto sua forma digital, como este artigo objetiva explicitar. Assim, dialoga-se com o surgimento e potencialização das TICs para o acesso a esses documentos audiovisuais jornalísticos, especialmente em ambientes digitais de informação.

Dessa forma, com o processo de digitalização do produto audiovisual Saccomori (2016) observa a existência de uma alteração em toda a cadeia audiovisual, desde a produção até o seu consumo online. Ainda de acordo com a autora, essa migração estabelece novos modos de uso a partir das mudanças estabelecidas do acesso vídeo analógico para o ambiente digital. Essa mudança de paradigma tem sido gradativamente visualizada, principalmente ao observar o cenário do mercado audiovisual com o aumento da produção audiovisual no YouTube ou na utilização da plataforma Vimeo, em que muitos trabalhos estão sendo arquivados, principalmente pela política de direitos autorais. Além disso, encontra-se novas plataformas de arquivamento e disponibilização como é o caso do IGTV do Instagram e os serviços de streaming audiovisuais internacionais

\footnotetext{
${ }^{1}$ O discente pode optar por realizar alguns dos laboratórios disponíveis na matriz curricular do curso de Jornalismo como, por exemplo, o Laboratório de Impresso, Fotojornalismo, Telejornalismo, Jornalismo Digital ou Assessoria de Imprensa.
} 
como a Netflix, Disney +, HBO, Hulu, Amazon Prime e o Globoplay, como um serviço de streaming nacional que vem ganhando destaque e relevância e estebelecendo um diálogo entre a TV e Internet.

Ao observar a realidade no âmbito universitário, compreende-se que a disponibilização dos conteúdos audiovisuais na plataforma digital é uma forma de espalhamento para o acesso e uso, bem como de preservação desses documentos audiovisuais. Esse processo pode ser concebido sob o prisma do diálogo com as novas tecnologias como a exemplo da convergência tecnológica. Como relata Jenkins (2009), tem-se na contemporaneidade um diálogo entre o meio de comunicação digital e os novos consumidores que estão presentes nesse ambiente informacional. Assim, verifica-se a necessidade do processo de migração e digitalização do audiovisual frente às novas possibilidades estabelecidas pelas ferramentais digitais.

Especificamente no caso do Curso de Jornalismo da UFCA - e, que pode servir como modelo para outras instituições, o arquivamento tem um impacto não somente para a comunidade acadêmica, mas para a sociedade como, por exemplo: a) acessar ao que foi produzido (como no caso dos produtos audiovisuais jornalísticos dos estudantes); b) estabelecer um diálogo com os outros estudantes (a partir da visualização das temáticas dos produtos audiovisuais jornalísticos, modos de produção, construção do roteiro); c) preservação das memórias dos produtos audiovisuais, dos estudantes e do curso; e) extrapolar as barreiras de acesso físico para além dos muros da universidade e; f) a possibilidade de práticas e modos de operacionalização para o desenvolvimento de um banco de dados ou sistema de memória audiovisual digital.

Na compreensão da produção desses arquivos e documentos audiovisuais, Cajazeira e Souza (2019a, p. 3-4) explicitam que,

Os documentos e arquivos audiovisuais sempre estiveram presentes na sociedade. É uma forma de registrar as informações, a partir da utilização de outros suportes informacionais. Assim, pode-se destacar as organizações jornalísticas, com ênfase para as emissoras de TV, como grandes potencializadoras desse tipo de arquivo. São elas que demonstram uma preocupação com os processos de armazenamento e recuperação, principalmente, devido ao grande volume de imagens produzidas diariamente.

Mas, para além das empresas jornalísticas e emissoras de TV, as universidades, com foco nos cursos de Jornalismo e na produção audiovisual dos estudantes desenvolvem centenas de horas de produtos audiovisuais como podem ser vislumbradas nas disciplinas de telejornalismo e na realização do TCC produto audiovisual. E, com isso, torna-se necessário a criação de um sistema de armazenamento audiovisual que possa corroborar para o armazamento desses documentos e com a construção de uma cultura do arquivamento dessas memórias audiovisuais. Uma cultura que não ainda não tem sido visualizada nestes ambientes e que é pouco explicitada seja na prática ou mesmo em pesquisas científicas.

Desta forma, compreende-se a importância do que Nora (1993) explicita como os lugares de memória. São lugares que funcionam como registros e lembranças humanas, exteriores a partir da necessidade de criar arquivos, pois estes lugares são criados a partir da condição de que não há memória espontânea, sendo necessária a criação desses lugares (físicos) nos quais são concebidos como marcos testemunhais de outros tempos e épocas. Perpassando os estudos de Nora (1993) e dialogando com os ambientes digitais de informação, entende-se que "com o advento da tecnologia digital observa-se a introdução dos novos lugares da memória, bem como um aumento da capacidade de armazenamento e processamento da expansão da memória para além do espaço físico" (CAJAZEIRA; SOUZA, 2019b, p. 5, grifo nosso). Esses novos lugares da memória podem funcionar como potencializadores da memória, mas que ainda são pouco explorados pelos ambientes de informação - principalmente, do audiovisual universitário e que dialoga com a presente proposta de investigação.

\section{Procedimentos Metodológicos}

A realização da pesquisa parte de uma abordagem quanti-qualitativa dos produtos audiovisuais jornalísticos, a partir da objetividade e subjetividade do estudo, pois esse modelo possibilita a observação de questões a serem melhor aprofundadas tanto quantitativa como qualitativamente (MINAYO; SANCHES, 1993). Além disso, parte-se do levantamento bibliográfico sobre o temas discutidos na pesquisa e a coleta dos produtos audiovisuais na coordenação do Curso de Jornalismo e na biblioteca central da UFCA, no campus Juazeiro do Norte. O recorte de produtos audiovisuais analisados compreende 0 período de 2013 a 2019.1, visto que a pesquisa não pode coletar os dados do semestre 2019.2, pois os estudantes ainda não tinham realizado o depositado dos TCCs até o momento da realização do estudo. 
A investigação também se caracteriza como um estudo de caso, que possibilita o pesquisador a observar uma realidade (YIN, 2005), como no caso do Curso de Jornalismo da UFCA. E, faz uso da pesquisa descritiva, realizando uma observação de forma satisfatória sobre as diversas dimensões do objeto de estudo. Para Richardson (2011), a pesquisa de natureza descritiva tem como seu objetivo a descrição sistemática de determinado fenômeno ou área do saber, a qual se deseja investigar, de modo objetivo e detalhado.

\section{Análise e discussão dos resultados}

No levantamento dos produtos audiovisuais desenvolvidos para o TCC do Curso de Jornalismo da UFCA foram identificados 22 produtos (Quadro 2), que comporeendem o período correspondente de análise da pesquisa (2013.2 e 2019.1). Estes são os TCC que já haviam sido apresentados pelos estudantes e já estavam depositados, por isso a coleta ocorreu até o semestre 2019.1.

Quadro 2 - Produtos audiovisuais jornalísticos para o Trabalho de Conclusão de Curso de Jornalismo

\begin{tabular}{|c|c|}
\hline Ano & Quantidade \\
\hline 2013 & 2 \\
\hline 2014 & 2 \\
\hline 2015 & 2 \\
\hline 2016 & 2 \\
\hline 2017 & 6 \\
\hline 2018 & 6 \\
\hline 2019 & 2 \\
\hline
\end{tabular}

Fonte: Elaborado pelos autores.

$\mathrm{Na}$ tabela 1 é possível observar a quantidade de produtos audiovisuais jornalísticos, que foram elaborados pelos estudantes do curso. É possível visualizar uma crescente na produção e interesse em realizar como TCC um produto audiovisual. De 2013 a 2016 o número de produtos não se verifica uma mudança quantitativa, assim, foram identificados 2 produtos por ano. Porém, a partir de 2017 a 2019 - compreendendo apenas o primeiro semestre - constata-se um crescimento exponencial: cerca de $300 \%$ a mais em comparação com os anos anteriores. Ou seja, os estudantes têm demonstrado o interesse pela produção de produtos audiovisuais jornalísticos como modelo de TCC.

Além disso, é possível vislumbrar que esses produtos estão divididos em duas categorias o documentário televisivo e a grande reportagem televisiva, como podem ser visto a seguir:

Quadro 3 - Quantidade de documentos por ano e tipologia

\begin{tabular}{|c|c|c|}
\hline Ano & $\begin{array}{c}\text { Documentário } \\
\text { Televisivo }\end{array}$ & $\begin{array}{c}\text { Grande Reportagem } \\
\text { Televisiva }\end{array}$ \\
\hline 2013 & 2 & 0 \\
\hline 2014 & 1 & 1 \\
\hline 2015 & 1 & 1 \\
\hline 2016 & 2 & 0 \\
\hline 2017 & 5 & 1 \\
\hline 2018 & 4 & 2 \\
\hline 2019 & 2 & 0 \\
\hline
\end{tabular}

Fonte: Elaborado pelos autores.

Sendo assim, os dados obtidos explicita a existência de um crescimento pela produção audiovisual do Curso de Jornalismo da UFCA para a realização do TCC. O que dialoga diretamente com os interesses dos estudantes, por exemplo, em poder acessar e assistir ao que já foi produzido pelos estudantes de turmas anteriores para observar como foram realizados, suas temáticas, recorte e seleção de imagens, enquadramento da câmera, estética entre outros aspectos técnicos e visuais de produção e edição desses TCCs.

Diante da visualização do aumento na elaboração desses produtos audiovisuais para o TCC, enfatiza-se a necessidade do arquivamento e disponibilização desses arquivos, seja na versão física ou digital - uma vez que na atual realidade ambas as formas não acontecem. O que estabelece a criação de um barreira, acarretando na usabilidade e no consumo dos produtos 
audiovisuais, pois devido a falta do arquivamento desses produtos audiovisuais e sua disponibilização para consulta e acesso seja na biblioteca ou na coordenação do curso, o seu uso fica restrito como no caso desta pesquisa que obteve autorização para acessar tais produtos.

Porém, esse processo de visualização não pode ser feito atualmente já que a disponibilização não ocorre. Assim, essas memórias audiovisuais produzidas pelos estudantes encontram-se estocadas em um armário na coordenação do Curso de Jornalismo (figura 1) e na sala de tratamento da biblioteca central do campus Juazeiro do Norte, levando essas imagens ao esquecimento. Com isso, esse estoque informacional de TCCs, na realidade atual, só pode ser usado pela equipe desses ambientes de informação ou por pesquisadores que solicitam o seu acesso. O que não corrobora com os objetivos e ideias da universidade de democratização da informação e logo do conhecimento.

Figura 1 - Armazenamento dos TCCs audiovisuais na coordenação do curso

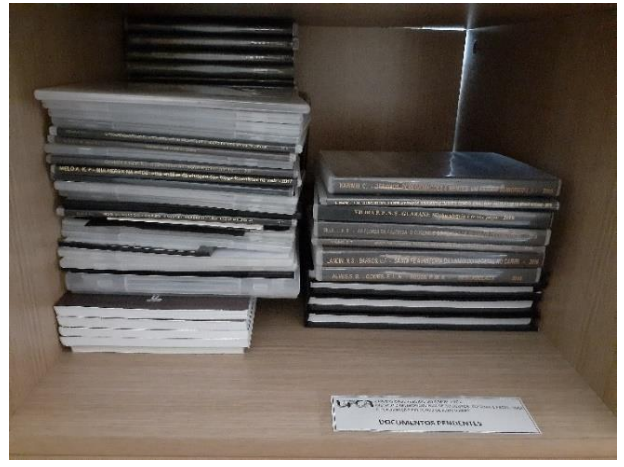

Fonte: Elaborado pelos autores.

Neste sentido, é na etapa do arquivamento que se verifica a principal problemática, que orientou a realização desta pesquisa e que compreende as demais etapas: acesso, uso, recuperação e disseminação da informação. O que torna inviável que os novos estudantes do curso possam obter algum tipo de aprendizado a partir da visualização destes produtos audiovisuais, haja visto a dificuldade da obtenção do acesso e mesmo da organização destes produtos: que não estão organizados em uma lista de controle, por exemplo. Assim, coube aos pesquisadores a tarefa de realizar a listagem e a organização dos dados desses TCCs para a coleta e identificação dos dados.

Ou seja, ao visualizar a falta de uma cultura do arquivamento também se observa um descaso em relação aos TCCs produtos audiovisuais jornalísticos da UFCA, como no caso dos TCCs. Esses produtos deveriam estar disponíveis no Sistema de Bibliotecas da UFCA (Sibi), visto que os primeiros produtos datam do ano de 2013 - e, também da própria coordenação do Curso de Jornalismo, como forma de controle e organização da produção dos estudantes. Mas, não é o que se verifica ao buscar esses arquivos seja física ou virtualmente.

Deste modo, no contexto das TICs e da presença dos ambientes digitais de informação é possível identificar possíveis lugares de armazenamento da memória audiovisual, a exemplo do próprio site da instituição, do Curso de Jornalismo ou ainda no Sibi da UFCA. Assim, esses lugares que poderiam funcionam para a preservação e preservação da memória, não têm a sua funcionalidade e potencialidade utilizadas para tal finalidade.

Em relação ao site do Curso de Jornalismo, por exemplo, identifica-se que o mesmo possui um lugar reservado para o armazenamento como Biblioteca Online, na qual se apresenta um lugar para a inserção dos TCC produtos e monografias (figura 2). Mas, que ao acessá-lo não é visualizado nenhum arquivo em sua página. 
Figura 2 - Biblioteca online do curso de jornalismo
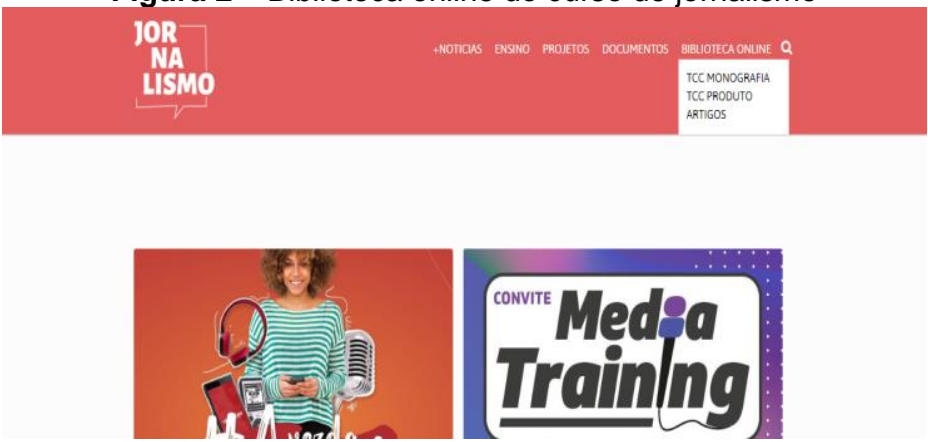

Fonte: http://www.jornalismo.ufca.edu.br/

No entanto, dentro da próprio Curso de Jornalismo identifica-se uma proposta de arquivamento e disseminação da produção audiovisual a partir do site da disciplina de telejornalismo. O site criado em 2015, procura armazenar as produções desenvolvidas nas disciplinas de telejornalismo, o que pode ser visto como um modelo a ser seguido pelo curso, visto que os TCCs não estão disponíveis no site da disciplina - pois, é preciso considerar questões de direitos autorais para que eles possam ser armazenados.

Além do site, as produções audiovisuais dos estudantes também estão armazenadas em redes sociais digitais a exemplo do YouTube (figura 3) e Facebook (figura 4). A utilização de tal recurso deve-se em primeiro lugar ao uso massivo dessas redes sociais digitais na contemporaneidade, a facilidade de acesso via dispositivos móveis como smartphones e o acesso à internet via rede móvel. Ou seja, foram os recursos existentes no momento para a difusão destes produtos audiovisuais.

Figura 3 - Canal do YouTube da disciplina de Telejornalismo

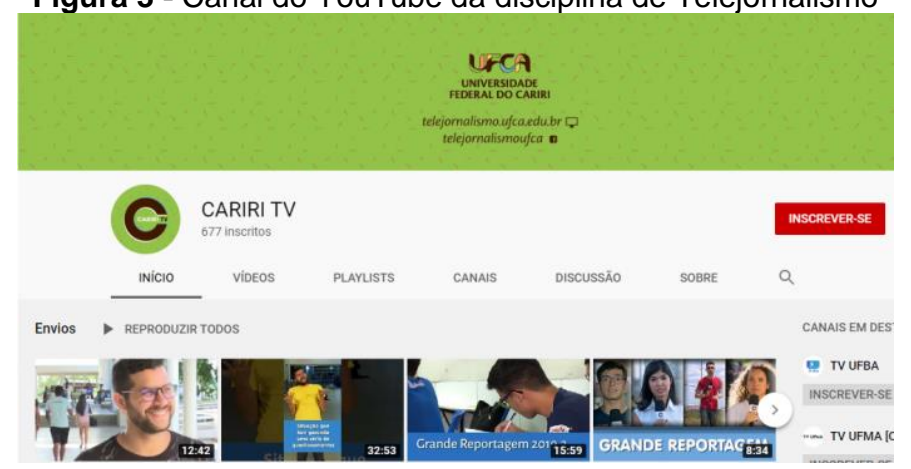

Fonte: https://www.youtube.com/user/TVComunicacaoCariri

O uso da plataforma do YouTube, pelo Curso de Jornalismo da UFCA teve suas primeiras experiencias de arquivamento e compartilhamento das produções dos estudantes, possuindo 677 inscrições (até a realização deste estudo) e 169 produções armazenadas. O canal foi criado em 10 de outubro de 2012 e desde então funciona como um lugar de memória situado no ambiente digital de informação. A fanpage do Facebook também foi uma ferramenta utilizada pela disciplina, para disponibilizar o acesso aos produtos audiovisuais dos estudantes.

Figura 4 - Fanpage da disciplina de Telejornalismo

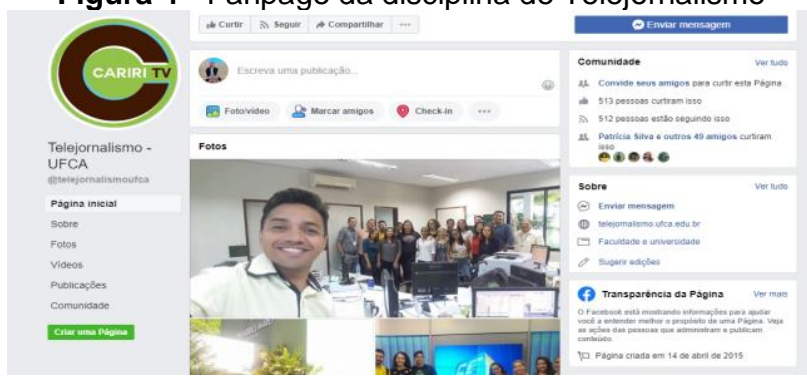

Fonte: https://www.facebook.com/telejornalismoufca/ 
A fanpage foi criada em 14 de abril de 2015, porém encontra-se desatualizada tendo a sua última publicação em 15 de setembro de 2017. Em decorrência da observação, essa desatualização e uso do Facebook é vista com o surgimento do site da disciplina (figura 5), que foi criado em 25 de junho de 2015 e tem sido o principal lugar de armazenamento e disponibilização em conjunto com o YouTube.

Figura 5 - Site do curso da disciplina de Telejornalismo Telejornalismo

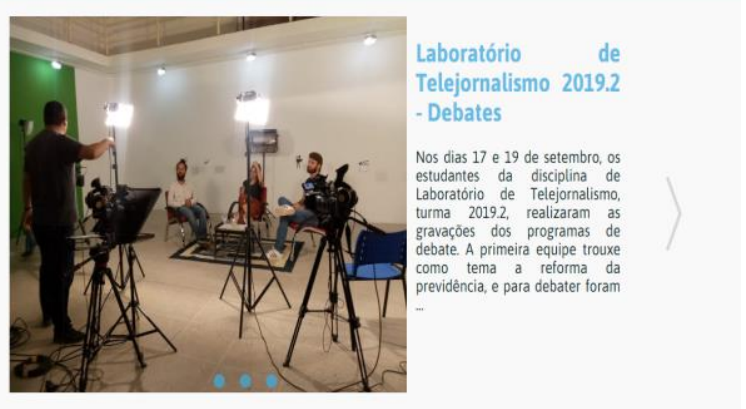

Fonte: http://telejornalismo.ufca.edu.br/

No site da disciplina de telejornalismo é possível encontrar produtos inseridos na plataforma digital como os telejornais, programas de entrevista, debates, reportagens e até mesmo documentários. Esses arquivos e documentos audiovisuais estão dispostos no site na aba "produções", no item "galeria". Nessa subdivisão o usuário, pode acessar diversas produções realizadas pelos estudantes de turmas diferentes. E, sendo inseridas todas as produções do curso que estão disponíveis no canal do YouTube desde 2012, que antecedem a criação do site no ano de 2015.

Neste sentido, é fundamental compreender esses lugares - para o arquivamento, acesso, recuperação e disponibilização do conteúdo audiovisual possibilitam que os estudantes possam aprender sobre a produção audiovisual, consumir esses produtos - como uma forma de dar mais visibilidade e expansão e estabelecendo um intercâmbio entre a universidade e sociedade, a partir da integração e interação entre as turmas, os usuários internos e externos da instituição e na interação e, também, com os produtos. Além disso, cria-se um sistema de memória audiovisual que possibilita a realização de pesquisas e construção da paisagem audiovisual midiática universitária.

Visto que, a não disponibilização destes TCCs audiovisuais recai no seu esquecimento como pode ser visualizado. E, por possuírem um peso maior, considerando que o estudante já passou por todas as disciplinas e apresentou o produto para um banca de avaliação, essas produções audiovisuais são fundamentais para auxiliar no aprendizado de novos estudantes do Curso de Jornalismo. Sobretudo, aos que desejam também produzir um TCC produto audiovisual.

\section{Considerações Finais}

Frente a realidade apresentada do Curso de Jornalismo da Universidade Federal do Cariri, com base nos produtos audiovisuais desenvolvidos para o Trabalho de Conclusão de Curso compreende-se a necessidade e a importância das práticas do arquivamento audiovisual universitário que levam a questões como disponibilização, acesso, aprendizado e formas de consumo na contemporaneidade. Assim, ao visualizar neste estudo de caso a ausência da prática do arquivamento audiovisual e da criação de um sistema de memória, destaca-se que esses produtos audiovisuais estão sendo direcionados para o esquecimento da memória, dos estudantes e da produção do curso.

Desse modo, ao não vislumbrar atividades de preservação como uma atividade que deveria ser proposta pelo Curso de Jornalismo como um todo, o professor responsável pela disciplina de telejornalismo observou nos ambientes digitais de informação um lugar de memória para o arquivamento e disseminação dos produtos, inicialmente com o canal do YouTube e o Facebook. E, posteriormente, com a criação do site da disciplina de telejornalismo, em que concentra-se toda a produção dos estudantes atualmente. Porém, não abarca a memória dos TCCs produtos audiovisuais jornalístico. Nesta perspectiva, 
ainda encontra-se a necessidade de desenvolver políticas e um olhar mais atencioso para os TCCs, visando a sua preservação e acesso.

Uma vez que as atividades de preservação não são vistas pela coordenação do curso ou pela biblioteca, que é a principal responsável pela disseminação dos TCCs, é preciso considerar que a demanda de trabalho desses lugares informacionais é grande e a quantidade de profissionais não seja suficiente. Porém, apenas isso não justifica o fato de que desde o ano de 2013 até o início de 2020, esses TCCs ainda não estejam disponíveis e a realidade continue sendo a mesma: o esquecimento dessas memórias audiovisuais. Com isso, o ambiente universitário, visto como espaço para a reflexão, inovação e desenvolvimento de novas práticas entra em conflito com a falta da disponibilização desses produtos audiovisuais. Produtos que resguardam e revelam a memória da sociedade, do curso e da produção dos estudantes sem uma finalidade que demonstre uma utilidade pública, que gera informação e conhecimento.

Neste sentido, as práticas que já vem acontecendo com os produtos das disciplinas de telejornalismo, podem servir como exemplos e também para que o próprio site da disciplina de telejornalismo possa disponibilizar esses produtos - observando a questão de direito autorais e propriedade intelectual, com o consentimentos dos estudantes. E, também o site do próprio curso já que possui um espaço destinado para essa finalidade, porém não é utilizado e pressupõe a visualização da falta de uma cultura do arquivamento, na qual se pode considerar como um problema de estrutura institucional - não somente no caso da UFCA, mas uma realidade mais abrangente de outras instituições - e da falta de políticas de arquivamento. Um processo que extrapola as fronteiras do simples arquivar, mas que visa o compartilhamento, guarda, preservação, acesso e disponibilização da memória desses produtos audiovisuais dessas memórias audiovisuais.

\section{Referências}

BARRETO, Aldo de Albuquerque. Uma história da ciência da informação. In: TOUTAIN, Lídia Maria Batista Brandão. (Org.). Para entender a ciência da informação. Salvador: EDUFBA, 2007.

CAJAZEIRA, Paulo Eduardo Silva Lins; SOUZA, José Jullian Gomes de. Acervo audiovisual e virtualização: as potencialidades da tecnologia digital para a preservação da memória. Rizoma, Santa Cruz do Sul, v. 7, n. 1, p. 122, junho, 2019a. Disponível em: https://online.unisc.br/seer/index.php/rizoma/article/view/12823/8278 Acesso em: 12 abr. 2020.

CAJAZEIRA, Paulo Eduardo Silva Lins; SOUZA, José Jullian Gomes de. A memória virtualizada do arquivo audiovisual jornalístico. In: ENCONTRO NACIONAL DE PESQUISA EM CIÊNCIA DA INFORMAÇÃO, 20., 2019b, Florianópolis. Anais [...]. Florianópolis: UFSC, 2019. Disponível em: https://conferencias.ufsc.br/index.php/enancib/2019/paper/view/474 Acesso em: 12 abr. 2020.

JENKINS, Henry. Cultura da convergência. Tradução Susana Alexandria. 2. ed. São Paulo: Aleph, 2009.

MINAYO, Maria Cecília de S; SANCHES, Odécio. Quantitativo-qualitativo: oposição ou complementaridade? Cadernos de Saúde Pública, Rio de Janeiro, v. 9, n. 3, p. 239-262, jul./set., 1993. Disponível em: http://www.scielo.br/pdf/csp/v9n3/02.pdf Acesso em: 9 abr. 2020.

NORA, Pierre. Entre memória e história: a problemática dos lugares. Revista Projeto História, São Paulo, v. 10, jul./dez., 1993. Disponível em: https://revistas.pucsp.br/revph/article/view/12101/8763 Acesso em: 9 abr. 2020.

RICHARDSON, Roberto Jarry. Pesquisa social: métodos e técnicas. 3. ed. São Paulo: Atlas, 2011.

SACCOMORI, Camila. Práticas de binge-watching na era digital: novas experiências de consumo de seriados em maratonas no Netflix. 2016. 246 f. Dissertação (Mestrado em Comunicação Social). Programa de Pós-Graduação da Faculdade de Comunicação Social, Pontifícia Universidade Católica do Rio Grande do Sul, Rio Grande do Sul, 2016. Disponível em: http://hdl.handle.net/10923/8331 Acesso em: 9 abr. 2020

TÁRTAGLIA, Ana Renata; BUTRUCE, Débora. Entre letras e imagens: o acervo audiovisual do arquivo da Academia Brasileira de Letras. Revista do Arquivo Geral da Cidade do Rio de Janeiro n. 9, 2015, p.327-340. Disponível em: www.pro.rio.ri.gov.br/revistaagcri/wpcontent/uploads/2016/11/e09 a19.pdf Acesso em: 05 jul. 2019.

UNIVERSIDADE FEDERAL DO CARIRI. Projeto Pedagógico do Curso de Jornalismo. Juazeiro do Norte: UFCA, 2016. Disponível em: https://documentos.ufca.edu.br/wp-folder/wp-content/uploads/2019/08/JornalismoUFCA-Projeto-Pol\%C3\%ADtico-Pedag\%C3\%B3gico2016.pdf Acesso em: 6 dez. 2019.

YIN, Robert. Estudo de caso. Tradução: Daniel Grassi. 3. Ed. Porto Alegre: Bookman, 2005.

Artigo submetido em: 08/01/2020. Aceito em: 15/04/2020 


\section{URIVERSIDADE FEDERAL DO CARIRI}

Centro de Ciências Sociais Aplicadas

Mestrado Profissional em Biblioteconomia

Este periódico é uma publicação do Programa de Pós-Graduação em Biblioteconomia da Universidade Federal do Cariri em formato digital e periodicidade quadrimestral. 